\title{
O FUNDO PARA A CONVERGÊNCIA ESTRUTURAL COMO INSTRUMENTO DE DESENVOLVIMENTO REGIONAL NO MERCOSUL
}

Fabricio Jose Missio ${ }^{1}$

\section{INTRODUÇÃO}

A organização do mundo em blocos regionais não é algo recente e não surgiu repentinamente. Faz parte da estratégia de alianças econômicas, políticas e militares de um conjunto de países que, principalmente após a guerra fria, buscam na integração dos mercados uma oportunidade de crescimento econômico e desenvolvimento social. Nesse contexto, Brasil e Argentina, que já tinham acordos de integração comercial desde a década de 1980, lideram a criação de um bloco na América do Sul, denominado de Mercado Comum do Sul (MERCOSUL).

Com o objetivo principal de facilitar a livre circulação de bens, serviços e fatores produtivos, os países signatários do MERCOSUL deveriam buscar ao longo do tempo a adoção de uma política comercial comum, com o estabelecimento de uma Tarifa Externa Comum (TEC), bem como a coordenação de posições conjuntas em foros internacionais, a formulação conjunta de políticas macroeconômicas e setoriais e, pôr fim, a harmonização das legislações nacionais com vistas a uma maior integração.

Inicialmente, por meio da assinatura do tratado de Assunção (1991), Argentina, Paraguai, Uruguai e Brasil deram início ao processo que culminou na formação do bloco. Posteriormente, a Venezuela, em 2012, ingressou nesse grupo de países denominados Estados Partes. Outros países se integraram na qualidade de convidados, sendo estes Estados Associados: a Bolívia (em processo de adesão), o Chile (desde 1996), o Peru (desde 2003), a Colômbia e o Equador (desde 2004) a Guiana e Suriname (desde 2013).

Os países que integram os chamados Estados Partes participam das reuniões institucionais com direito a voto, já os países que constituem os Estados Associados podem participar apenas como convidados. A ênfase da atuação do MERCOSUL tem sido o comércio intra bloco, ou seja, melhorar as relações comerciais entre os países membros, que cresceu de forma significativa desde sua criação. Além dos aspectos econômicos, o bloco tornou-se um importante ator no processo político da região, como na atuação, em 1996, para impedir uma tentativa de golpe militar no Paraguai, ameaçando expulsar o país do grupo de países membros.

Além disto, o MERCOSUL tem ampliado o escopo de atuação e, nos dias atuais, sua ação tem diversas dimensões que vão desde as políticas educacionais até as relacionadas ao mercado

\footnotetext{
1 Professor Assistente do Departamento de Economia da Universidade Federal de Minas Gerais(UFMG). E-mail: fabriciomissio@gmail.com.
} 
de trabalho, ou desde aquelas relacionadas a agricultura até as ligadas as atividades industriais, entre outras. Ou seja, atualmente o bloco tem atuado no sentido de avançar na integração regional a partir da construção/adoção de políticas que estão além dos simples acordos comerciais, superando, assim, uma primeira fase de liberalização comercial, quando da institucionalização do bloco. Nesse processo de consolidação, o MERCOSUL vem se aprimorando institucionalmente, com a criação do Tribunal Permanente de Revisão, do Instituto Social, do Instituto de Políticas Públicas de Direitos Humanos e, em destaque, com a criação do Fundo para a Convergência Estrutural do MERCOSUL (FOCEM), objeto de análise deste trabalho. O respectivo fundo é responsável pelo financiamento de projetos de convergência estrutural e coesão social, contribuindo para amenizar as diferenças econômicas e sociais entre os países partes.

Nesse contexto, considerando que a integração dos países membros do MERCOSUL é importante para o desenvolvimento regional da América do Sul e, em especial, para o Brasil, e considerando que o país tem alguns projetos em execução no território nacional que buscam a convergência estrutural, é pertinente analisar a importância do FOCEM enquanto instrumento capaz de diminuir as assimetrias regionais. Assim, o objetivo do trabalho é caracterizar e analisar a atuação do fundo, buscando compreender seu alcance e suas limitações enquanto instrumento de desenvolvimento regional.

Justifica-se a realização deste trabalho pela limitação de análises envolvendo o fundo, principalmente no campo do desenvolvimento regional e estudos fronteiriços, e pela importância do tema, tendo em vista que as desigualdades entre os países e regiões da América Latina, embora rotineiramente objeto de análise, permaneçam como característica histórica da estrutura econômica e social local. Do ponto de vista metodológico, inicialmente realiza-se uma pesquisa bibliográfica sobre as teorias de desenvolvimento e integração regional. Em seguida, apresentase uma descrição dos fundos de convergência (ou similares) implantados em outros blocos para, posteriormente, discutir a origem e a estrutura do FOCEM, na tentativa de compreender seu alcance e suas limitações. Por fim, apresenta uma discussão acerca da funcionalidade do FOCEM enquanto instrumento do desenvolvimento regional.

Para cumprir com o objetivo, o artigo está organizado em quatro seções, além desta introdução e das considerações finais. Na seção 2 retomam-se brevemente as teorias de desenvolvimento e da integração regional e suas inter-relações; na seção seguinte apresentamse os principais blocos econômicos e uma breve análise de como eles se utilizam da criação de fundos para promoção do desenvolvimento. Em seguida (seção 4), apresenta-se uma discussão sobre a origem do FOCEM, objetivos e projetos em execução no Brasil; enquanto na última seção analisa-se o fundo enquanto instrumento de desenvolvimento regional no MERCOSUL. 


\section{DESENVOLVIMENTO REGIONAL E INTEGRAÇÃO}

As pesquisas e análises sobre o desenvolvimento regional começaram a ganhar destaque com a crise de 1929, quando se evidencia o problema das desigualdades regionais na maioria dos países industrializados. Tal situação viria a mudar a concepção do papel do Estado. Segundo Diniz (2009), até aquele momento a questão regional era tratada apenas em termos da localização das atividades agrícolas e industriais, como nos trabalhos de Von Thune, Weber e Losch².

Com a crise surgem novas interpretações que avançam em termos de proposições teóricas e em termos da proposição de práticas e técnicas de planejamento capazes de reduzir as referidas desigualdades. Destacam-se, por exemplo, Walter Isard (1956) com a sua teoria locacional e François Perroux (1955) com a teoria sobre o conceito de polos de crescimento e o papel da empresa motriz para o crescimento desses polos 3 .

Então, grosso modo, pode-se identificar que esse "segundo grupo de teorias", que tem significativa influência até meados da década de 1980, compreende aquelas que enfatizam as interdependências setoriais como fator de localização das firmas e de desenvolvimento da região, incorporando a ideia de economias externas e de mecanismos dinâmicos que se autorreforçam endogenamente, indo além da preocupação com a localização individual das firmas. As principais teorias representativas desse grupo (já bem conhecidas) são: i) A teoria dos polos de crescimento de Perroux; ii) $O$ modelo de Causação Circular Cumulativa, de Myrdal; iii) O "Círculo Vicioso da Pobreza" de Nurkse; e, iii) $O$ modelo de Interdependência e Efeitos de Encadeamento de Hirschman.

Posteriormente, destaca-se um "terceiro grupo de teorias" que incorporam externalidades dinâmicas do tipo marshallianas e que se subdividem em duas abordagens distintas: a primeira tem como autor protagonista Paul Krugman (1991 a,b; 1995). Fochezatto (2010) argumenta que o autor considera três tipos de economias marshallianas para explicar o fenômeno da localização industrial: concentração do mercado de trabalho, oferta de insumos especializados e intercâmbio

\footnotetext{
${ }^{2}$ Esses autores têm a distância e a área como foco central de suas teorias e a preocupação básica é definir modelos de localização da produção de forma a minimizar os custos de transporte. São teorias estáticas e que se limitam a quantificar os custos e os lucros na determinação da localização ótima da firma numa determinada região (FORCHEZATTO, 2010). Ou ainda, segundo Ferreira (1989), essas contribuições são entendidas como os fundamentos básicos das teorias da localização e da análise da organização espacial da economia. Para uma análise critica sobre teorias da localização ver Azzoni (1982).

${ }^{3}$ Em meados dos anos 1970 países em desenvolvimento e desenvolvidos chegaram a utilizar ou discutir as estratégias de desenvolvimento regionais baseadas na teoria de Perroux, sem muito sucesso, pois o efeito de difusão das inovações tecnológicas geradas dentro das indústrias dos polos provocou um aumento da concentração regional das atividades econômicas, muito provavelmente causado pela ausência de um planejamento econômico nacional que levasse em consideração os polos regionais de crescimento (CAVALCANTE, 2008).
} 
tecnológico. Essas economias não explicam como o processo de aglomeração começou, mas conseguem explicar como ele se autorreforça, tornando-se cumulativo e duradouro.

A segunda abordagem é constituída por autores evolucionistas e institucionalistas, como Becattini e Storper, que também passaram a incorporar em seus modelos as economias marshallianas, agregando os retornos crescentes e atribuindo um papel importante aos agentes locais na organização dos fatores e na coordenação do processo cumulativo. Assim, enquanto 0 processo cumulativo de Krugman passa principalmente pelo sistema de preços e pelo mercado, nos evolucionistas e institucionalistas ele passa principalmente pela interação e pela coordenação entre os agentes. A novidade desta segunda abordagem é o protagonismo dos atores na definição do modelo de desenvolvimento, em contraposição ao planejamento centralizado ou as livres forças de mercado.

Não obstante, na América Latina o desenvolvimento regional contou com a influência teórica da Comissão Econômica para a América Latina - CEPAL, através da contribuição de autores como Raúl Prebisch, Celso Furtado, Aldo Ferrer, Noyola Vásquez, entre outros. Nesse caso, fica mais explícita a associação entre as teorias de desenvolvimento regional e o papel da integração. Segundo José Antonio Ocampo "a integração foi e continua sendo um sonho cepalino" (HAFFNER, 2002).

Vale lembrar que a análise histórica do subdesenvolvimento empreendida por Prebisch (1949), sintetizada na diacronia e sincronia da relação centro-periferia, além de ser uma interpretação do desenvolvimento capitalista na perspectiva dos países latino-americanos, constituiu-se num significativo contraponto às teses neoclássicas do comércio internacional. Portanto, as teses sobre a deterioração dos termos de intercâmbio na relação centro-periferia e seu movimento cíclico desdobraram na elaboração de um projeto diferenciado de industrialização e desenvolvimento pare os países periféricos (Koling, 2000).

Nesse contexto, passado a fase inicial da industrialização substitutiva, uma série de condicionantes internos foram apontados como elementos que impediam a consolidação da segunda fase dinâmica da industrialização. Dentre esses destacam-se a própria insuficiência dinâmica dessa industrialização e as exigências de padrões tecnológicos às indústrias dinâmicas, a falta de poupança interna, de mercado consumidor, a escassez de divisas internacionais, o padrão de ocupação da mão-de-obra, da concentração da terra e a disparidade no consumo das elites (Prebisch, 1964; Tavares, 1983). Segundo Koling (2000), a integração regional e/ou subregional passou a ser então assunto de pauta na discussão da Cepal, pois viria ao encontro da desobstacularização das insuficiências nacionais. 
Uma das insuficiências apontadas era decorrente do fato de que para continuar o processo de industrialização, os países da região dependiam dos mercados dos países centrais para obter a maior parte dos seus ganhos de divisas necessárias a aquisição das importações requeridas para manter o ritmo de atividades econômicas. Nesse caso, dado a deterioração dos termos de troca e dada a baixa especialização produtiva (o que significa baixa incorporação do progresso técnico), é possível verificar a existência de uma debilidade estrutural entre o comércio dos países da América Latina com os países centrais. Essa debilidade em muitos casos, transforma-se em "asfixia externa" (crise da dívida).

Portanto, para contornar essa insuficiência era necessário avançar no processo de integração regional. Assim, com o aumento das importações da própria região os países poderiam pagar por elas exportando manufaturados que outros países da região importam do centro. Em outras palavras, a integração fornece uma saída para o problema da falta de divisas, pois 0 comércio intra-regional permite no curto prazo maior utilização da capacidade instalada. Ademais, o regionalismo permite menor uso de divisas e a busca do equilíbrio comercial (Baumann, 2000).

Furtado (2000) também argumenta que a integração regional seria capaz de oferecer saídas para superar as desvantagens dos países em desenvolvimento frente aos países industrializados, possibilitando o rompimento da baixa produtividade e o pouco dinamismo dessas economias. Assim, a maior integração promoveria a união das economias de aglomeração às economias de escala, sendo esta, portanto, uma etapa superior da teoria do desenvolvimento. Nesse contexto, a política de integração começa a desempenhar papel de política de desenvolvimento e, consequentemente, o planejamento da integração surge como uma forma mais complexa de coordenação das decisões econômicas.

Evidentemente, a experiência histórica tem mostrado que o sucesso de uma integração regional, em seus mais diferentes níveis, depende de muitos fatores, dentre os quais se destacam a estabilidade institucional, a existência de regimes democráticos, a diplomacia e a coordenação.

\section{BLOCOS ECONÔMICOS E FUNDOS DE CONVERGÊNCIA}

A globalização econômica e a necessidade de integração entre os países contribuíram para a emergência da formação de blocos econômicos. Além do MERCOSUL, existem blocos econômicos que possuem diversas formas e extensão, como as zonas de livre comércio, as uniões aduaneiras, as uniões econômicas e monetárias e as zona de preferência tarifária (Tabela 1). 
Tabela 1 - Principais blocos econômicos

\begin{tabular}{|l|l|l|r|}
\hline \multicolumn{2}{|c|}{ Lista dos principais Blocos Econômicos } & formado em: \\
\hline MERCOSUL & Mercado Comum do Sul & União aduaneira & 1991 \\
\hline ALALC & Associação Latino-americana de Livre Comercio & zona de preferencia tarifária & 1960 \\
\hline ALADI & Associação Latino-americana de Integração (substitui ALALC) & zona de preferencia tarifária & 1980 \\
\hline NAFTA & North American Free Trade Agreement: & zona de livre comercio & 1988 \\
\hline EU & União Europeia & união economica e monetária & 1957 \\
ALCA & Area de Livre Comercio das Americas & zona de livre comercio & 1994 \\
\hline APEC & Associação Economica para Cooperação da Ásia e do Pać́fico & zona de livre comercio & 1989 \\
CEI & Comunidade dos Estados Independentes & união economica e monetária & 1991 \\
AEC & Associação dos Estados do Caribe & zona de livre comercio & 1994 \\
\hline ANZCERTA & Acordo comercial sobre relações economicas entre Austrália e Nova Zelândia & zona de livre comercio & 1983 \\
\hline ASEAN & Associação de Nações do Sudeste Asiático & zona de livre comercio & 1967 \\
CAN & Comunidade Andina & zona de livre comercio & 1977 \\
CARICOM & Mercado Comum e Comunidade do Caribe & zona de livre comercio & 1973 \\
EFTA & Associação Europeia de Livre Comércio & zona de livre comercio & 1960 \\
MCCA & Mercado Comum Centro Americano & zona de livre comercio & 1960 \\
SADC & Comunidade para o Desenvolvimento da África Austral & zona de livre comercio & 1980 \\
UMA & União do Magreb Árabe & zona de livre comercio & 1989 \\
\hline
\end{tabular}

Fonte: http//www.camara.gov.br/mercosu//blocos/acesso em 22/02/2016 - elaboração dos autores

Do ponto de vista econômico, a formação desses blocos é importante pois facilita a interação comercial intrabloco (mas não só a integração comercial, como também a produtiva, financeira e monetária), em grande parte porque adotam-se medidas de redução das tarifas alfandegárias e de impostos que incidem sobre as exportações e importações, bem como porque adotam-se incentivos que visam facilitar o deslocamento de fatores produtivos (especialmente 0 capital). A união de países normalmente ocorre com parceiros comerciais, em geral, vizinhos geograficamente, que tenham semelhanças culturais e de desenvolvimento, o que não elimina as assimetrias previamente existentes. Em alguns casos, pode-se encontrar em sua estrutura organizativa a constituição de comitês ou fundos criados especificamente para ajudar a corrigir as assimetrias intra e inter-regionais dos países-membros.

Segundo Assunção (2013), o conceito de fundos estruturais está intimamente ligado com a integração regional: trata-se de um instrumento estrutural que ajuda os estados-membros num processo de integração a reduzir as disparidades sociais e econômicas, estabilizando a economia regional.

A seguir realiza-se um breve resgate de alguns dos principais blocos e fundos de ajuda mútua (enfatizando-se os chamados fundos estruturais). Não constitui objetivo fazer uma revisão detalhada a fim de esgotar o tema, mas apenas introduzir uma discussão acerca dos referidos fundos a partir de uma descrição dos modelos implantados em outros blocos para, em seguida, analisar o caso do FOCEM no MERCOSUL.

Entre os blocos econômicos já estabelecidos, o mais consolidado e com uma larga trajetória que remonta a meados do século passado é a União Europeia (UE), que possui como um dos seus objetivos a integração social e econômica da Europa, considerando o passado de rivalidades 
e disputas que conduziram a inúmeros conflitos. Em 1972, o Fundo Europeu de Desenvolvimento Regional (FEDER) foi criado para dar suporte ao momento de dificuldades econômicas que a Europa se encontrava, agravado pela crise do petróleo, bem como para corrigir o atraso socioeconômico que alguns países (como a Irlanda) e algumas regiões (como algumas regiões da Inglaterra que apresentavam forte desindustrialização) apresentavam em relação aos demais membros da União Europeia. A distribuição dos recursos ocorre de maneira inversa em relação à posição das regiões diante do PIB per capita médio (GALVÃO, 2004). Vale ressaltar que o FEDER continua atuando para corrigir os principais desequilíbrios regionais da União Europeia, apoiando o desenvolvimento de regiões com maior atraso socioeconômico.

Outro fundo existente na União Europeia com importante papel na redução das assimetrias é o Fundo Social Europeu (FSE), principal instrumento para promover o emprego e a inclusão social4 ${ }^{4}$ O FSE tem como objetivo ajudar as pessoas a encontrar emprego (ou eventualmente trocar por outro que ofereça melhores condições), integrar as pessoas desfavorecidas na sociedade e garantir melhores oportunidades. Por ano, o FSE consegue atingir aproximadamente 15 milhões de pessoas. Assim, o fundo é considerado importante no curto prazo porque atenua as consequências das crises econômicas, enquanto no longo prazo propicia uma sociedade mais inclusiva.

Na década de 1990 aumentou significativamente a percepção asiática sobre a necessidade de se criar (ou aprofundar) espaços institucionais e instrumentos mais efetivos, capazes de propiciar uma maior cooperação monetária e financeira na região (CUNHA, 2008). Surgiam (ou aprofundaram-se) diversas iniciativas regionais de integração do Leste Asiático, dentre os quais destacam-se: i) Asia-Pacific Economic Cooperation (APEC); ii) East Asia Summit (EAS ou ASEAN+6); iii) ASEAN+3; iv) Asian Development Fund; v) East Asia Economic Caucus (EAEC); vi) Association of Southeast Asian Nations (ASEAN), entre outras. Não obstante, apesar de uma série de acordos e fundos de desenvolvimento, os mesmos não se assemelham aos fundos de convergência.

O fundo para a convergência estrutural (FOCEM) criado pelo MERCOSUL no ano de 2006 se assemelha ao fundo europeu. A equipe que constitui o fundo é formada com representantes indicados pelas chancelarias e ministérios da economia e da fazenda dos países-membros, com o objetivo de identificarem iniciativas e programas que promovam a competitividade dos estados partes e a convergência estrutural, bem como fórmulas de financiamento para realizá-las. Sua

\footnotetext{
${ }^{4} \mathrm{O}$ bloco da União Europeia tem ainda, como parte da sua estrutura, comitês das regiões como um espaço consultivo, onde se discute a legislação e seus impactos sobre as regiões e cidades, ou ainda, questões relacionadas ao emprego, política social, coesão econômica e social, transportes, energia e mudanças climáticas. Ou seja, os comitês regionais têm voz ativa.
} 
criação é considerada a principal iniciativa formalmente constituída para o enfrentamento das assimetrias na América do Sul, mesmo que formado inicialmente apenas por quatro países ${ }^{5}$.

\section{FOCEM: ORIGEM, OBJETIVOS E PROJETOS NO BRASIL}

Quanto o MERCOSUL foi constituído, os países signatários do bloco apresentavam grandes assimetrias entre si, situação que permanece até o presente. Mesmo assim, apenas as perspectivas comerciais dominaram a primeira década de formação do bloco. Não obstante, observou-se que, com o passar do tempo, era necessário avançar em termos de uma integração mais completa e profunda entre seus membros, que incorporasse outras dimensões tanto econômicas quanto sociais 6 . Ademais, admitiu-se a necessidade de se corrigir as referidas assimetrias existentes entre os membros do bloco. Os dados a seguir (Tabela 2) apresentam, de uma maneira geral, uma perspectiva das assimetrias que ainda permanecem na região.

Tabela 2-A - Desigualdades regionais entre os países do MERCOSUL

\begin{tabular}{|l|r|r|r|r|r|r|r|}
\hline & PIB 2013 & \multicolumn{1}{c|}{$\%$} & POPULAÇÃO 2013 & \% & RENDA PER CAPITA & TERRITÓRIO & $\%$ \\
\hline BRASIL & 2.243 .854 & 67,75 & 202.033 .670 & 70,88 & 11.199 & 8.515 .767 & 66,52 \\
\hline ARGENTINA & 611.726 & 18,47 & 41.803 .125 & 14,67 & 14.760 & 2.791 .810 & 21,81 \\
\hline URUGUAI & 55.708 & 1,68 & 3.418 .694 & 1,20 & 16.351 & 176.220 & 1,38 \\
\hline PARAGUAI & 29.208 & 0,88 & 6.917 .579 & 2,43 & 4.294 & 406.750 & 3,18 \\
\hline VENEZUELA & 371.379 & 11,21 & 30.851 .343 & 10,82 & 12.213 & 912.050 & 7,12 \\
\hline & 3.311 .875 & & 285.024 .411 & & 58.817 & 12.802 .597 & \\
\hline & & & & & & & \\
\hline Fonte: IBGE; elaboração da autora & & & & & & & \\
\hline
\end{tabular}

Tabela 2-B - Desigualdades regionais entre os países do MERCOSUL

\begin{tabular}{lrrrrr} 
& \multicolumn{1}{l}{ IDH $^{1}$} & \multicolumn{1}{c}{ GIN| $^{2}$} & Desemprego $^{3}$ & Pobreza $^{4}$ & (Imp+Exp)/PIB $^{5}$ \\
\hline BRASIL & 0,755 & 52,87 & 7,3 & 15,1 & $21,5 \%$ \\
\hline ARGENTINA & 0,836 & 42,28 & 4,8 & 4,7 & $25,6 \%$ \\
\hline URUGUAI & 0,793 & 41,87 & 8 & 11,5 & $37,2 \%$ \\
\hline PARAGUAI & 0,679 & 48,3 & 6,9 & 23,8 & $71,0 \%$ \\
\hline VENEZUELA & 0,762 & 46,94 & 7,8 & 32,1 & $39,5 \%$ \\
\hline
\end{tabular}

Notas: 1) Referente ao ano de 2014; 2) Referente ao ano de 2013, exceto para Venezuela que representa 0 ano de 2006; 3) Em \%, média no ano de 2014, exceto para Venezuela, média dos dois primeiros trimestres de 2014; 4) Percentual da população em situação de pobreza, referente ao ano de 2013. Para a Argentina só está disponível a informação para áreas urbanas. 5) Fluxo comercial como proporção do PIB no ano de 2013.

Fonte: IBGE, Banco Mundial, Programa das Nações Unidas para o Desenvolvimento, CEPAL; elaboração dos autores.

Segundo ARSLANIAN (2012, p. 86), "a integração é uma convergência normativa e uma solidariedade econômica, social e, às vezes, até política". Ela é, portanto, uma etapa superior à

\footnotetext{
${ }^{5}$ Argentina, Paraguai, Uruguai e Brasil. Posteriormente, a Venezuela começou a fazer parte do Fundo.

${ }^{6} \mathrm{O}$ processo de integração do Mercosul pode ser dividido nas seguintes fases: i) Predomínio da agenda comercial 1991 - 1997; ii) Crise na integração 1998 - 2002; e, iii) Retomada do processo integracionista a partir de 2003. Ver, entre outros, Benedetti (2014).
} 
integração comercial, pois envolve além do desenvolvimento de políticas econômicas comuns, 0 aperfeiçoamento dos instrumentos de saúde, de educação, de segurança, etc.

Nesse contexto, o MERCOSUL tem avançado nos últimos anos em direção a uma integração mais efetiva. Duas ações tomadas em 2010 servem de exemplo para evidenciar a trajetória recente do bloco (ARSLANIAN, 2012, p. 86):

i) Quando se decidiu unificar as placas de todos os veículos dos quatro países do Mercosul e que se adotaria uma cédula de identidade única para todos os cidadãos, o objetivo foi o de criar um cadastro único, sustentado por um banco de dados, de forma a permitir a identificação de veículos e cidadãos em qualquer local que se encontrassem, dentro do território aduaneiro do Mercosul. Só com isso é que será possível almejar a livre circulação de veículos e pessoas, consolidando assim a integração;

ii) Quando se estabeleceu a eliminação da dupla cobrança, o objetivo foi o de obter a livre circulação de mercadorias dentro do bloco. Seria difícil, senão impossível, pretender criar cadeias de integração produtiva, com a participação conjunta de produção setorial entre empresas de nacionalidades distintas dentro do território aduaneiro, se um insumo importado tivesse que pagar imposto alfandegário cada vez que passasse de um país para outro, ao seguir o ciclo produtivo, por meio da agregação de valor. Uma verdadeira integração deve implicar necessariamente que um produto importado, ao pagar a tarifa externa comum (TEC), deve ser considerado "originário", ou seja, passa a ser um produto Mercosul - e não brasileiro ou uruguaio - seja onde ele estiver.

Além disso, como já mencionado criou-se o FOCEM, no intuito de diminuir as assimetrias regionais. $O$ fundo tem por objetivo desenvolver a competitividade e promover a coesão social, em particular das economias menores integrantes do bloco e das regiões menos desenvolvidas, bem como apoiar o funcionamento da estrutura institucional e fortalecer o processo de integração (CAETANO, 2011).

Neste sentido, instituíram-se as normas para o funcionamento do fundo, que estabelecem quatro programas de atuação, a saber:

i) Programa de convergência estrutural, que possibilita a execução de projetos que poderão contribuir para o desenvolvimento e ajuste estrutural das economias menores e regiões menos desenvolvidas, inclusive na melhora da integração fronteiriça e dos sistemas de comunicação. Pode ainda contemplar, também, projetos de construção, modernização e recuperação de vias de transporte que aperfeiçoem o escoamento de produção e promovam a integração física entre os países e entre suas regiões, a exploração de combustíveis fósseis e biocombustíveis; a geração e transporte de energia elétrica; obras de infraestrutura hídrica e de saneamento ambiental (CAETANO, 2011, pg. 19-69). 
ii) Programa de desenvolvimento da competitividade das atividades produtivas, que inclui 0 reordenamento dos processos produtivos e trabalhistas que facilitem a criação do comércio intraMERCOSUL. Neste sentido, procura contemplar projetos de integração de cadeias produtivas com vistas à melhora na qualidade dos produtos e aumento de pesquisas e para geração de novos produtos e processos produtivos, como certificações; geração e difusão de conhecimentos tecnológicos; promoção de setores e cadeias produtivas; fortalecimento e associatividade de pequenas e médias empresas vinculando-as aos mercados regionais, promover e desenvolver novos empreendimentos; contribuir na profissionalização, autogestão; cooperativismo; associativismo e incubação de empresas (CAETANO, 2011, pg. 19-69).

iii) Programa de coesão social, que prevê uma contribuição para o desenvolvimento social, em particular nas zonas de fronteira, podendo contemplar projetos de interesse da comunidade em áreas de saúde, redução e combate da pobreza e desemprego, escolas, capacitação e certificação de trabalhadores; identificação e localização das áreas mais afetadas pela exclusão social, promover ajuda comunitária, acesso a moradia, educação, alimentação dos setores mais vulneráveis das regiões de fronteira.

iv) Programa de fortalecimento das instituições e do processo de integração, referente aos projetos para a melhoria da estrutura institucional do MERCOSUL, discutindo e avaliando a eficácia e a atuação das diversas instâncias que compõem o arcabouço institucional do bloco. Além disto, visa garantir que os projetos executados pelo FOCEM sejam concluídos de maneira eficiente e que após sua execução continuem contribuindo com as instituições dos estados partes, procurando, desta forma, o aprimoramento de todo o processo de integração regional (PINTO, 2012).

O aporte financeiro de recursos é proporcional ao grau de desenvolvimento e o volume da economia de cada país e a utilização dos mesmos é realizado numa lógica inversa ao que foi aportado. Sendo assim, o Brasil é o maior contribuinte, aportando 70\% dos recursos do Fundo; a Argentina é responsável pela integralização de $27 \%$ do montante; o Uruguai, pela contribuição de $2 \%$ e o Paraguai de $1 \%$. As duas menores economias do bloco são as maiores beneficiárias dos projetos: enquanto o Uruguai é contemplado com $32 \%$ dos recursos o Paraguai recebe $48 \%$.

Com operações desde 2007, o FOCEM conta atualmente com uma carteira de projetos superior a US\$ 1,5 bilhões. Ao longo de seu funcionamento, o fundo já apoiou 45 projetos distribuídos da seguinte forma: 17 apresentados pelo Paraguai, 12 pelo Uruguai, 4 pela Argentina, 4 pela própria secretaria do MERCOSUL ou outro órgão da estrutura funcional do bloco, 3 projetos pluri estatais e 5 pelo Brasil. Os projetos aprovados e em execução nos países membros referemse, em sua maioria, a construção de edifícios para educação, a melhorias em termos do 
esgotamento sanitário e, especialmente, a projetos de infraestrutura como a manutenção ou construção de rodovias e manutenção de vias férreas. Evidencia-se, assim, o reconhecimento de que o setor de transporte é um dos maiores entraves da produção e do desenvolvimento na região.

Outros projetos que tiveram um aporte significativo estão relacionados a área energética, pois as deficiências nesse setor são consideradas um obstáculo real para a ampliação dos fluxos dos fatores produtivos intrabloco. Isso implica, por exemplo, na redução da competitividade do MERCOSUL em termos da concorrência internacional. Um desses projetos é da construção de linhas de transmissão, construção de subestações e ampliação das mesmas pela Itaipu-Villa Hayes que foi apresentado em conjunto pelo Brasil e Paraguai.

No caso brasileiro, os projetos apoiados (em execução e análise) pelo fundo concentramse no centro-sul do país e encontram-se distribuídos, segundo o Ministério do Planejamento, Orçamento e Gestão, conforme Tabela 3. Cumpre ressaltar que a utilização dos recursos pelo Brasil em projetos de interesses subnacionais reafirma a possibilidade de correção das assimetrias regionais e, mais ainda, a apresentação de projetos para benefício plurinacional, como o caso dos projetos de adensamento das cadeias produtivas ou de erradicação da febre aftosa, revelam a funcionalidade do Fundo para o aprofundamento da integração econômica.

Tabela 3 - Projetos em execução no Brasil, levantamento ano de 2016.

\begin{tabular}{|c|c|c|c|c|}
\hline PROJETOS & ENTIDADE EXECUTORA & SITUAÇÃO & CONVÊNIO & VL.TOTAL \\
\hline Programa de ação Mercosul livre de febre aftosa & $\begin{array}{l}\text { Ministério de Agricultura, Pecuária e } \\
\text { abastecimento }\end{array}$ & em execução & $28 / 06 / 2007$ & $\$ 16.339 .470$ \\
\hline $\begin{array}{l}\text { Implantação da biblioteca UNILA e Instituto Mercosul de estudos } \\
\text { avançados }\end{array}$ & $\begin{array}{l}\text { Universidade Federal do Paraná - } \\
\text { UFPR }\end{array}$ & em execução & $02 / 08 / 2010$ & $\$ 22.000 .000$ \\
\hline $\begin{array}{l}\text { Construção linhas de transmissão 500KV Itaipu-Villa Hayes, } \\
\text { subestação e ampliação }\end{array}$ & Itaipu Binacional & em execução & $09 / 09 / 2010$ & $\$ 555.000 .000$ \\
\hline Ampliação do sistema de Saneamento de Ponta Porã/MS & $\begin{array}{l}\text { Empresa de saneamento de Mato } \\
\text { Grosso do Sul }\end{array}$ & em execução & $01 / 12 / 2010$ & $\$ 6.136 .206$ \\
\hline $\begin{array}{l}\text { Adensamento e complementação automotiva no âmbito do } \\
\text { Mercosul }\end{array}$ & $\begin{array}{l}\text { Agencia Brasileira de } \\
\text { Desenvolvimento Industrial - ABDI }\end{array}$ & em execução & $16 / 12 / 2010$ & $\$ 3.930 .438$ \\
\hline $\begin{array}{l}\text { Qualificação e Integração de Fornecedores da Cadeia produtiva } \\
\text { de Petróleo e Gas }\end{array}$ & \begin{tabular}{|l} 
Agencia Brasileira de \\
Desenvolvimento Industrial - ABDI
\end{tabular} & em execução & $17 / 12 / 2010$ & $\$ 3.672 .236$ \\
\hline Investigação, Educação e Biotecnologias Aplicadas a Saúde & Fundação Oswaldo Cruz & em execução & $20 / 12 / 2011$ & $\$ 10.061 .400$ \\
\hline Saneamento Urbano das cidades de Aceguá-BRA e Aceguá-UR & $\begin{array}{l}\text { Companhia Riograndense de } \\
\text { Saneamento }\end{array}$ & em execução & $06 / 11 / 2013$ & $\$ 7.640 .524$ \\
\hline Obras de Engenharia de Esgotamento Sanitário de São Borja/RS & $\begin{array}{l}\text { Companhia Riograndense de } \\
\text { Saneamento }\end{array}$ & em execução & $\begin{array}{l}\text { aguardando assinatura } \\
\text { do COF }\end{array}$ & $\$ 9.967 .536$ \\
\hline $\begin{array}{l}\text { Implantação e pavimentação trecho viário BR282/BR283 } \\
\text { Chapecó/SC }\end{array}$ & Prefeitura municipal de Chapecó/SC & em análise pela UTF/SM & & \\
\hline Complementação da Infraestrutura do Parque Tecnologico Itaipu & Itaipu Binacional & em análise pela UTF/SM & & \\
\hline Modernização do Laboratório de Referencia Enológica - LAREN & $\begin{array}{l}\text { LAREN -laboratorio de referencia } \\
\text { enologica }\end{array}$ & em análise pela UTF/SM & & \\
\hline $\begin{array}{l}\text { Assistência técnica e extensão rural para qualificação da produção } \\
\text { de uva e derivados no estado do RS }\end{array}$ & Governo do Estado do RS & \multicolumn{2}{|c|}{ em análise pela UTF/SM/BRASIL } & \\
\hline Promoção Institucional e Comercial do vinho gaúcho & Governo do Estado do RS & \multicolumn{2}{|c|}{ em análise pela UTF/SM/BRASIL } & \\
\hline $\begin{array}{l}\text { Obras de Engenharia de infraestrutura de estradas na cidade de } \\
\text { Vila Flores/RS }\end{array}$ & Prefeitura municipal de Vila Flores/RS & \multicolumn{2}{|c|}{ em análise pela UTF/SM/BRASIL } & \\
\hline $\begin{array}{l}\text { O telescópio BINGO - Oscilações Acústicas de Bárions a partir } \\
\text { de Observações Inegradas de Gás Neutro }\end{array}$ & $\begin{array}{l}\text { IFUSP - Instituto de Física da USP e } \\
\text { INPE - Instituto Nacional de } \\
\text { Pesquisas Espaciais }\end{array}$ & \multicolumn{2}{|c|}{ em análise pela UTF/SM/BRASIL } & \\
\hline
\end{tabular}




\section{ANÁLISE DO FOCEM ENQUANTO INSTRUMENTO DE DESENVOLVIMENTO REGIONAL NO MERCOSUL}

A perspectiva de maior integração às economias latino-americanas e a possibilidade de formar um mercado relativamente importante em escala global coloca ao Brasil o desafio de ser o interlocutor principal entre as economias da região e o mercado internacional, dada as suas maiores dimensões (territoriais, econômicas, produtivas, etc). Recentemente, especialmente na primeira década do século corrente, o Brasil tem se apresentado como interlocutor no projeto de integração junto aos países membros, reconhecendo as soberanias nacionais e a responsabilidade dessa liderança. Não obstante, ressalta-se a necessidade de uma união supranacional regional que não reconheça somente o potencial econômico da região, mas suas características culturais e que a coloque como elemento fundamental de uma integração, capaz de destacar a região no cenário das relações internacionais (GUIMARÃES, 2006).

Nesse contexto, o FOCEM foi constituído tendo como objetivo corrigir as assimetrias econômicas regionais, ou ainda, encadear as economias da região de maneira a se complementarem. Considera-se que a criação do FOCEM e a consequente implementação do programa de convergência estrutural representou uma etapa importante no processo de integração regional, pois houve a percepção - especialmente por parte das duas maiores economias do bloco, Brasil e Argentina - da necessidade de contribuir com as economias da região e ceder maiores investimentos aos países (economias) menores, promovendo programas que intensificam a integração regional, a formação de cadeias produtivas regionais e os investimentos em tecnologia. A promoção da integração entre os povos do MERCOSUL e, em especial, as populações fronteiriças com o programa de coesão social representa a preocupação com políticas de integração (SILVA e JOHNSON, 2014).

Em outras palavras, implicitamente observa-se que o FOCEM implica no fortalecimento institucional do bloco, evidenciando a integração como processo paulatino de amadurecimento das relações entre os Estados envolvidos (COUTO, 2012).

O principal argumento econômico em prol da integração não é novo. A ideia, que reporta a Adam Smith, é de que a ampliação dos mercados via processo de integração geraria maior produtividade do trabalho (dado à possibilidade de maior especialização) e por consequência uma maior competitividade da produção. Essa maior competitividade se traduziria em maior poder de acumulação, responsável pela indução de novos e mais complexos processos produtivos da periferia (RODRIGUEZ, 2009). Para tanto, a correção das assimetrias torna-se fundamental e à criação de um fundo reforça essa percepção. 
Vale destacar que tais projetos de convergência podem contribuir para o reconhecimento e a valorização do objetivo maior, que é o projeto integracionista, já que os benefícios às regiões contempladas pode gerar uma identificação efetiva entre os cidadãos e a integração regional. Finalmente, apesar da limitação de recursos e de projetos apresentados (executados) pode-se destacar que, para regiões de fronteira, este tem se constituído num fundo eficaz para impulsionar o desenvolvimento local ou, pelo menos, minimizar as limitações estruturais de tais áreas. Em suma, o alcance dos programas do fundo tem uma preocupação solidária com os países de economias menores, onde projetos de coesão social podem impulsionar o crescimento e desenvolvimento econômico e, de certa forma, de todo o bloco.

\subsection{Apreciações críticas}

Admite-se, de uma perspectiva mais geral, que o enfrentamento dos problemas do FOCEM passa pelo aprofundamento do processo de integração. Ou seja, é preciso avançar em várias frentes, como já apontado pela literatura especializada, a fim de que se possa usufruir dos benefícios desse processo. Por exemplo, é necessário ampliar a consciência e disseminar a noção de que a integração traz benefícios para todos os envolvidos. Para isso, a população deve estar suficientemente informada e o Estado deve ser o interlocutor desse debate? ${ }^{7}$.

Ademais, ressalta-se que o conhecimento mútuo entre os estados membros é bastante limitado e, portanto, é preciso avançar nos estudos histórico-geográficos sobre a América do Sul. A falta de conhecimento impede que se explore justamente o que é uma das características mais importantes da região, ou seja, a diversidade dos países sul-americanos (tanto em termos cultural, institucional e social quanto em termos da culinária, das paisagens e das expressões culturais).

Em outras palavras, é preciso desenvolver não só projetos de integração, mas especialmente desenvolver um conhecimento, uma expertise aprofundada sobre cada país, individualmente. Ainda, é preciso desenvolver mecanismos de consulta popular para a definição de projetos que possam ter relevante impacto social e político, ampliando o sentimento da importância da participação coletiva (PATRIOTA, 2012). Por fim, é preciso urgentemente estabelecer e aprofundar uma política de transparência da gestão pública8 ${ }^{8}$.

\footnotetext{
${ }^{7}$ Algumas ações nesse sentido envolve a divulgação dos avanços por meio de livros escolares, de promoção de debates nas universidades, junto à sociedade em geral, etc.

8 Cumpre ressaltar a dificuldade em achar informações e dados referentes ao FOCEM, o que inviabilizou uma análise mais aprofundada em várias dimensões. $\mathrm{Na}$ era da tecnologia digital, a não sistematização e disponibilidade de informações (como em um sitio, por exemplo), é bastante questionável e prejudica a aceitação, a implementação e os resultados de qualquer política pública.
} 
Especificamente em relação ao Fundo existe uma série de deficiências que devem ser corrigidas. Em primeiro lugar, o aporte financeiro fornecido, limitado para a dimensão das assimetrias e a priorização de determinadas áreas tende a gerar uma sensação de insuficiência de recursos ou dos limites de sua aplicação ${ }^{9}$ (ou seja, nesse caso o aumento dos recursos indicaria um movimento de fortalecimento institucional do Fundo). Ademais, os mecanismos de distribuição (e execução) ainda carecem de aprimoramento de forma a torná-los eficazes e imunes aos descaminhos dos gastos públicos em certas regiões.

Couto (2012) chama atenção para este ponto. Segundo o autor, os projetos relacionados ao FOCEM partem dos estados nacionais sem uma diretriz macrorregional (supranacional) específica. Ademais, os critérios gerais de seleção não satisfazem a afirmação de uma estratégia planejada de desenvolvimento regional ou de coesão territorial, o que implica que o Fundo pode acabar respondendo por demandas nacionais pontuais, perdendo a visão ampla do combate às desigualdades territoriais. Em outras palavras, o risco é que os recursos sejam aplicados de forma desconexa, reduzindo, assim, sua capacidade de reduzis as assimetrias regionais.

A crítica do autor vai além ao afirmar que o fundo não articula planos de desenvolvimento locais ou regionais e, ao determinar políticas regionais de "cima para baixo", força atores locais a usarem de relações não-institucionalizadas para a apresentação de projetos. Falta, portanto, uma visão abrangente sobre o papel de cada espaço na estruturação do território integrado sulamericano.

Em segundo lugar, ressalta-se que a execução do Fundo pode ser aprimorada mediante a definição das relações com outros institutos financeiros que atuam na região, sejam eles bancos regionais e locais e/ou mecanismos de desenvolvimento regional como financiamentos conjuntos, que, no caso brasileiro, poderiam ser realizados através do Banco Nacional de Desenvolvimento Econômico e Social.

Em terceiro lugar, é preciso avançar na instrumentalização das políticas de coesão territorial. Segundo Couto (2012), de uma perspectiva multiescalar a atuação do FOCEM é frágil. A menção às zonas de fronteiras não basta para a construção de uma política de coesão territorial efetiva. As desigualdades a nível nacional são bem mais complexas de serem enfrentadas e já expressam o resultado da soma das desigualdades regionais que abarcam.

\footnotetext{
9 Benedetti (2014) mostrou que, comparativamente ao PIB, os desembolsos para os maiores beneficiários do Focem representaram: i) no caso do Paraguai cerca de 0,27\% do PIB em 2011, 0,7\% em 2012 e $0,35 \%$ em 2013; ii) no caso do Uruguai, esse percentual foi de $0,03 \%$ em 2011 , $0,1 \%$ em 2012 e $0,01 \%$ em 2013.
} 
Por fim, é preciso melhorar a operacionalização do Fundo. Observa-se que a apresentação de projetos ainda não dá conta de consumir todos os recursos regulares do Fundo, o que, para uma região que tem limitações de acesso ao mercado financeiro mundial, é certamente um desperdício de recursos. Por outro lado, destaca-se a pequena parcela dos recursos destinada ao desenvolvimento e integração produtiva, C,T\&I e pequenas e microempresas, que tenderiam a ser centrais numa estratégia de desenvolvimento regional baseada na competitividade (COUTO, 2012).

Em suma, apesar de considerar que o FOCEM constitui uma novidade e que necessita ser aprimorado, pode-se afirmar que o fundo tem desempenhado um importante papel, local e regional, contribuindo para o desenvolvimento. Evidentemente, como demonstrado, seu alcance continua limitado. A ampliação do fundo (tanto em termos de volume como de alcance) depende, em grande medida, do avanço da integração regional e da superação das assimetrias entre países e regiões pertencentes ao bloco.

\section{CONSIDERAÇÕES FINAIS}

Este trabalho procurou analisar como a integração regional e, mais especificamente, como a correção das assimetrias regionais pode contribuir para o desenvolvimento. Neste sentido, procurou-se discutir alguns aportes da teoria econômica do desenvolvimento, considerando a especificidade latino-americana e analisar o processo (ainda não plenamente consolidado) de integração regional (MERCOSUL). Em seguida, buscou-se analisar o papel desempenhado pelo FOCEM.

Nesse contexto, o que tem-se observado recentemente é a ampliação dos esforços das lideranças do MERCOSUL em consolidar a integração do bloco e diminuir significativamente as assimetrias regionais, embora as políticas adotadas ainda careçam de um tempo de maturação para uma melhor avaliação. De qualquer forma, o FOCEM é um passo importante já que 0 aprofundamento da integração regional depende da superação das assimetrias e da sensação de "melhor bem estar" das comunidades envolvidas, além da construção de mecanismos institucionais que garantam a promoção e consolidação desse processo.

Em outras palavras, admite-se que o FOCEM enquanto instrumento de desenvolvimento tem um enorme potencial, embora alguns desafios necessitem ser superados. Um dos desafios refere-se ao volume de recursos destinados ao fundo, que deve ser ampliado. Outro, considerando o caso brasileiro como exemplo, refere-se a necessidade de capacitação e da criação de mecanismos que facilitem o acesso a tais recursos por parte das região mais carentes e menos 
desenvolvidas, principalmente do norte e nordeste do país, o que, até o momento, não tem ocorrido. Mesmo as regiões fronteiriças necessitam ter ampliado o seu acesso aos recursos.

O Brasil, pelo seu tamanho e importância estratégica, pode desempenhar um papel mais efetivo no que se refere ao fortalecimento deste mecanismo, contribuindo para a ampliação e destinação adequada de recursos e apresentando um maior número de projetos (especialmente aqueles de caráter supranacionais). Neste sentido, o FOCEM se coloca como uma oportunidade para que o processo de integração regional se consolide e cumpra com seus objetivos principais, que é o de aumentar o bem-estar social da maioria da população e diminuir as desigualdades regionais.

\section{REFERÊNCIAS BIBLIOGRAFICAS}

ARgaWALA, A. N., SINGH, S. P. (org.). A Economia do Subdesenvolvimento. Centro Internacional Celso Furtado de Políticas para o Desenvolvimento. Contraponto, 2010.

ARSLANIAN, R. P. O Mercosul, do Tratado de Assunção até hoje. In: A América do Sul e a integração regional, Rio de Janeiro, p. 85-92, 2012.

ASSUNÇÃO, B. M. G. de. A Importância dos Fundos Estruturais no Desenvolvimento Empresarial Português: Uma Visão Prática a partir do IAPMEI. Relatório de estágio de mestrado em economia, na especialidade de economia industrial. In: Faculdade de Economia da Universidade de Coimbra, 2013.

AZZONI, C. R. Teoria da localização: uma análise crítica. São Paulo: IPE-USP, 1982.

BANCO MUNDIAL. Indicadores del desarollo mundial.

BAUMANN, R. A Integração Regional vista pela CEPAL. In Poletto, D.W. (org). 50 Anos do Manifesto da CEPAL. Porto Alegre: Edipucrs, pgs 115-120, 2000.

CAETANO, G. (org.). Mercosur: Breve historia, cronologia y marco institucional, Montevidéu: CEFIR, 2011.

CAVALCANTE, L. R. Produção Teórica em Economia Regional: Uma proposta de sistematização. Revista Brasileira de Estudos Regionais e Urbanos, v. 2, n. 1, p. 09-32, 2008.

CEPAL - Open Regionalism in Latin America and the Caribbean, 1994.

CEPALSTAT - Bases de Datos y Publicaciones Estadísticas. Disponível em: http://estadisticas.cepal.org/cepalstat/WEB_CEPALSTAT/Portada.asp. Acesso em: 27/05/2016

COUTINHO, M.; HOFFMANN, A. R.; KFURI, R. Raio-X da integração regional. Estudos e Cenários, p. 1-58, 2007.

COUTO, J. M. O pensamento desenvolvimentista de Raúl Prebisch. Revista Economia e Sociedade, Campinas, v. 16, n. 1 (29), 2007.

COUTO, L. F. Desenvolvimento, Integração e Assimetrias: Caminhos e Descaminhos da Aproximação Regional na América do Sul. Tese de Doutorado - Relações Internacionais, UFRJ, 225 f., Rio de Janeiro, 2012.

DINIZ, C. C. Celso Furtado e o Desenvolvimento Regional. Nova Economia, 19 (2), p. 227-249, maio-agosto, 2009. 
FERREIRA, C. M.C. As teorias da localização e a organização espacial da economia. In Haddd, P. (org). HADDAD, P. R. Economia regional: teorias e métodos de análise espacial. BNB/ETENE, Fortaleza, 1989.

FOCHEZATTO, A. Desenvolvimento regional: novas abordagens para novos paradigmas produtivos. In: CONCEIÇÃO, Octávio A. C. et al. (Org.). 0 ambiente regional. Porto Alegre: FEE, 2010.

FURTADO, C. Teoria e Política do Desenvolvimento Econômico, Ed. Paz e Terra, 2000.

GALVÃO, A. C. F. Política de desenvolvimento regional e inovação: a experiência da União Européia. Rio de Janeiro: Garamond, 2004.

GUIMARÃES, S. P. Desafios Brasileiros na Era dos Gigantes. Rio de Janeiro: Contraponto, 2006.

HAFFNER, J. A. H. A Cepal e a integração regional latino-americana. Analise Econômica, ano 20, número 37, março 2002.

HIRSCHMAN, A. O. Estratégia do Desenvolvimento Econômico. Rio de Janeiro: Fundo de Cultura, 1961. (Primeira edição: 1958)

INSTITUTO BRASILEIRO DE GEOGRAFIA E ESTATISTICA - IBGE. Contas Nacionais. Acesso em: 25/05/2016.

KOLING, P. J. Cepal e a integração latino-americana. In Poletto, D.W. (org). 50 Anos do Manifesto da CEPAL. Porto Alegre: Edipucrs, p. 135-140, 2000.

KRUGMAN, P. Geography and trade. Cambridge: MIT, 1991a.

. Increasing returns and economic geography. Journal of Political Economy, v. 99, n. 3, p. 483-499, 1991b.

Development, geography and economic theory. Cambridge: MIT, 1995.

The self-organizing economy. Qxford: Blackwell, 1996.

MYRDAL, G. Teoria Econômica e regiões subdesenvolvidas. Instituto Superior de estudos Brasileiros, 1960.

PATRIOTA, A. de A. Discurso Inaugural. In: A América do Sul e a integração regional, Rio de Janeiro, p. 9-17, 2012.

PINTO, R. C. I. La Ciencia Política desde el Sur. Asociación Uruguaya de Ciencia Política, 1416 de noviembre de 2012.

PREBISCH, R. O desenvolvimento econômico da América Latina e seus principais problemas. In: Revista Brasileira de Economia, FGV, set. 1949, ano 3, n . 3, p . 47-95.

Os obstáculos ao Mercado Comum Latino-Americano. In: WIONCZEK, Miguel et al. A integração econômica da América Latina. Rio de Janeiro: O Cruzeiro, p. 160-174, 1966.

PROGRAMA DAS NAÇÕES UNIDAS PARA O DESENVOLVIMENTO (PNUD).Ranking IDH Global 2014. Acesso em: 25/05/2016.

RABELLO, J. S. F. F. MERCOSUR: its emergence, framework, social rights, connection with Unasul, evolution perspectives. Revista CEJ, Brasilia, Ano XIII, n. 46, p. 21-38, jul./set. 2009.

RODRIGUEZ, O. O Estruturalismo latino-americano. Rio de Janeiro: Civilização Brasileira, 2009. 
SILVA, M. A. da; JOHNSON, G. A. (org.). Mercosul e Globalização: Dinâmicas e desafios da Integração regional, UFGD, 2014.

TAVARES, M. da C. Da substituição de importações ao capitalismo financeiro. 11. ed. Rio de Janeiro: Zahar, 1983.

Recebido em 16/11/2018.

Aceito para publicação em 20/03/2019.

Resumo: O Fundo para a Convergência Estrutural (FOCEM) do Mercado Comum do Sul (MERCOSUL) foi constituído para auxiliar no processo de desenvolvimento das regiões fronteiriças. Os projetos executados (ou em execução) financiados pelo referido fundo buscam melhorar a infraestrutura dos municípios e, assim, contribuir para o desenvolvimento local. Nesse contexto, o objetivo do artigo é caracterizar e analisar a atuação do FOCEM, tecendo considerações preliminares quanto a sua funcionalidade em termos do desenvolvimento regional. Os principais resultados mostram que o fundo tem contribuído para a diminuição das assimetrias regionais, apesar do seu limitado alcance.

Palavras-chave: Desenvolvimento, Integração, Fundo de Convergência.

Abstract: The Fund for Structural Convergence (FOCEM) of the Southern Common Market (MERCOSUR) was established to assist in development of border regions. The executed projects (or running) financed by the fund seeks to improve the infrastructure of municipalities and thus contribute to local development. In this context, the objective of this article is to characterize and analyze the performance of FOCEM platted preliminary considerations as its functionality in terms of regional development. The main results show that the fund has contributed to the reduction of regional asymmetries, despite its limited scope.

Keywords: Development, Integration, Convergence Fund. 